\title{
Primary hepatic angiosarcoma with multifocal metastases in the gastrointestinal tract
}

A 64-year-old man presented with a 2month history of melena. He also had a history of chronic renal disease, hypertension, and diabetes mellitus, and he had worked at a leather factory for decades. He was diagnosed as having primary hepatic angiosarcoma and had undergone right lobectomy 4 months before this admission. Esophagogastroduodenoscopy and colonoscopy failed to detect the bleeding source. Capsule endoscopy showed multiple small hemorrhagic spots in the small intestine. Anterograde double-balloon enteroscopy (DBE) demonstrated multiple ulcerative, sessile polyps with oozing in the small intestine and a $2.5-\mathrm{cm}$ tumor with hemorrhage in the distal jejunum ( $\bullet$ Fig. 1 a,b). The tumor was resected by polypectomy; however, intermittent melena was still present. Retrograde DBE demonstrated a $2.5-\mathrm{cm}$ ulcerative tumor with hemorrhage in the ascending colon ( Fig.1c), which was also removed by polypectomy. Histopathological examination of the ulcerative polyps and tumors showed spindle tumor cells arranged in solid sheets rich in minute vascular channels ( Fig.2a). Immunohistochemical study of tumor cells showed positivity for CD31 ( Fig.2b) and CD34 ( $\bullet$ Fig. 2c). A diagnosis of metastatic angiosarcomas was made. Although thalidomide was prescribed for the patient, he died within 3 months of the diagnosis.

Angiosarcoma, a rare high grade vascular malignant tumor, most frequently involves the skin and subcutaneous tissues. It can also occur in breast, liver, spleen, bone, ovaries, and the adrenal glands. The etiology of angiosarcoma is still unclear, but in recent decades, several environmental carcinogens such as Thorotrast, vinyl chloride and arsenic compounds have been thought to be associated with angiosarcoma [1]. The most common site of metastases of primary hepatic angiosarcoma is lung followed by spleen [2]. Intestinal metastases in primary hepatic angiosarcoma are extremely rare. The most common presenting symptoms of intestinal angiosarcoma include abdominal pain, hemorrhage, vomiting, anemia, and weakness. Early detection and diagnosis, followed by operative resection, re-

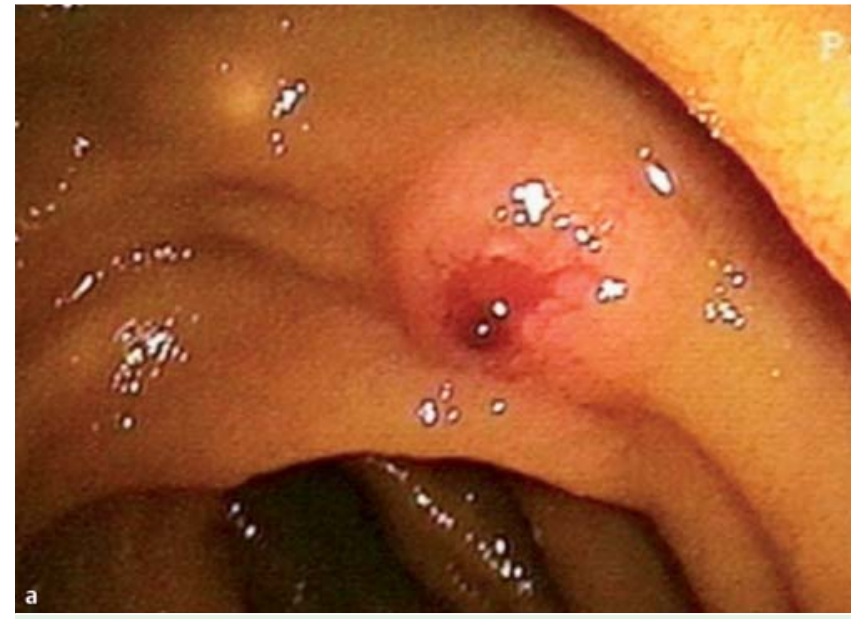

Fig. 1 a Anterograde double-balloon enteroscopy demonstrating multiple ulcerative sessile polyps with oozing in the small intestine in a 64-year-old man who presented with a 2-month history of melena.

b A 2.5-cm tumor with hemorrhage in the distal jejunum detected during the procedure. c Retrograde doubleballoon enteroscopy demonstrating a $2.5-\mathrm{cm}$

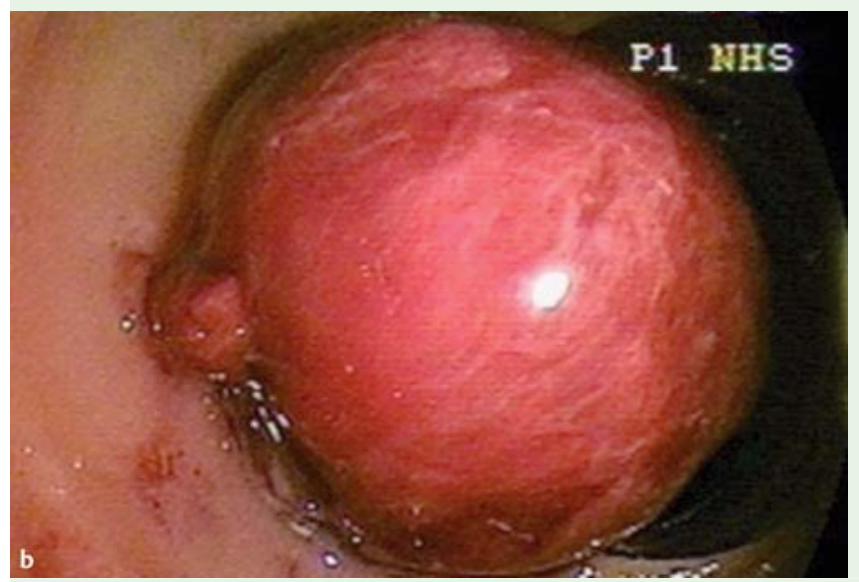
ulcerative tumor with hemorrhage in the ascending colon.

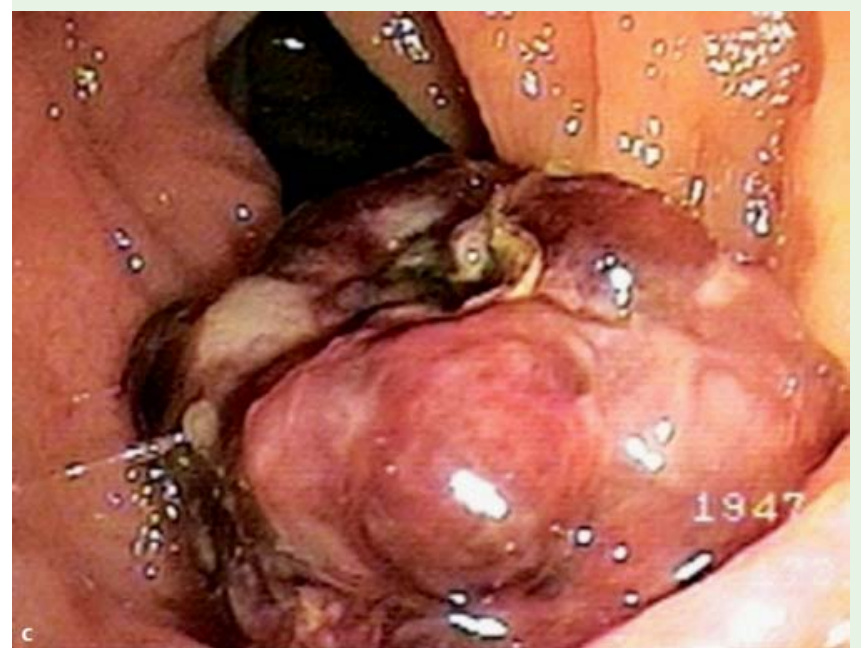

Endoscopy_UCTN_Code_CCL_1AC_2AC

mains the mainstay of management of this tumor and significant long-term survival. The prognosis of patients with angiosarcoma is very poor [3]. 

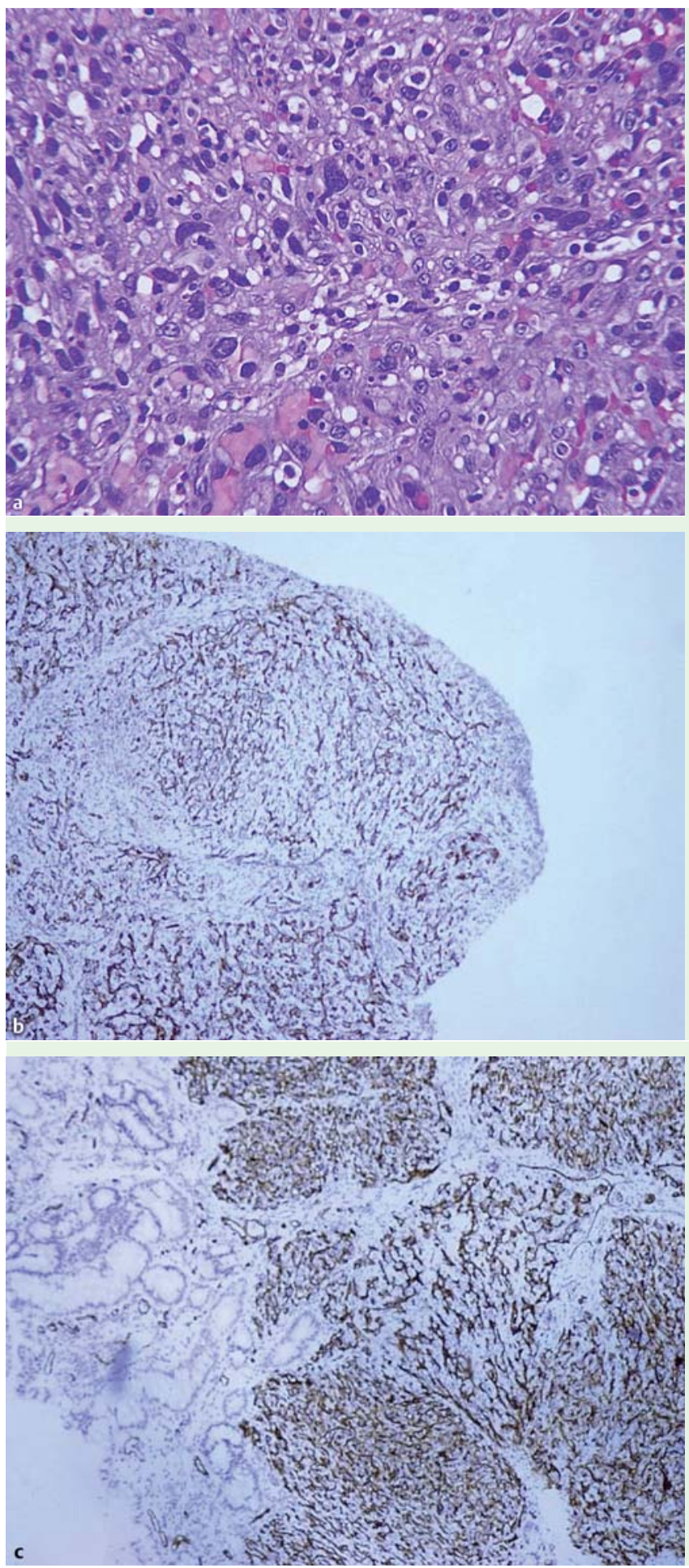

Fig. 2 a Histopathological section of the resected tumor showed spindle tumor cells arranged in solid sheets rich with minute vascular channels (hematoxylin and eosin, original magnification $\times 400$ ). b Immunohistochemical study of the tumor cells showing diffuse and strong positivity for CD31 (original magnification $\times 100)$. c Immunohistochemical study of tumor cells showing diffuse and strong positivity for CD34 (original magnification $\times 100$ ).
J. W. Chou ${ }^{1,2}$, K. S. Cheng ${ }^{1,2}$, S. F. Chen ${ }^{3}$

${ }^{1}$ School of Medicine, China Medical University Hospital, Taichung, Taiwan

${ }^{2}$ Division of Gastroenterology and Hepatology, Department of Internal Medicine, China Medical University Hospital, Taichung, Taiwan

${ }^{3}$ Division of Gastroenterology, Department of Internal Medicine, Chang Bing Show-Chwan Memorial Hospital, Changhua County, Taiwan

\section{References}

1 Popper H, Thomas LB, Telles NC et al. Development of hepatic angiosarcoma in man induced by vinyl chloride, Thorotrast and arsenic. Am J Pathol 1978; 92: 349-376

2 Locker GY, Doroshow JH, Zwelling LA et al. The clinical features of hepatic angiosarcoma: a report of four cases and a review of the English literature. Medicine 1979; 58: 48-64

3 Jaspreet SG, Amudha RM, Daniel EJ et al. Rapidly progressive metastatic multicentric epithelioid angiosarcoma of the small bowel: a case report and a review of literature. Int J Colorectal Dis 2008; 23: 745 - 756

\section{Bibliography}

DOI http://dx.doi.org/

10.1055/s-0033-1344574

Endoscopy 2013; 45: E319-E320

(c) Georg Thieme Verlag KG

Stuttgart · New York

ISSN 0013-726X

\section{Corresponding author}

\section{Dr S. F. Chen}

Division of Gastroenterology

Department of Internal Medicine

Chang Bing Show-Chwan Memorial Hospital

Changhua County

Taiwan

Fax: +886-4-7073226

nmx32001@yahoo.com.tw 